\title{
Explaining the Atlas Cedar (Cedrus atlantica M.) dieback by studying Water relations of young plants subject to an edaphic drought
}

\author{
Aadel Taoufik ${ }^{1}$, Rochdi Atmane ${ }^{2, *}$, Zine El Abidine Abdenbi ${ }^{3}$ \\ 'Forests and Water Department, Ministry of Agriculture, Rabat, Morocco \\ ${ }^{2}$ Ibn Tofail University, Faculty of Sciences, Kénitra, Morocco \\ ${ }^{3}$ National Forestry School of Engineers, BP: 511, Tabriquet, CP: 11000, Salé, Morocco
}

\begin{abstract}
Cedrus atlantica M. stands from the Middle Atlas Mountains in Morocco have been severely affected by dieback. The edaphic water deficit could be the cause that triggered this phenomenon leading to the mortality of dying trees. The objective of this work is to analyze the ecophysiological behavior of Atlas cedar seedlings subjected to an edaphic drought of progressive intensity. During the drying cycle, the relative moisture content of the substrate decreased significantly to reach $12.71 \%$ at the end of the test; $4.27 \%$ and $2.88 \%$ respectively for the basaltic, calcareous, and sandy substrate. The pre-dawn water potential reached very low values of $-32.25,-37.38$, and -39.50 bar at the end of the water drying cycle. The critical water potential varied between -36 and -39 bar depending on the type of substrate. The mean maximum stomatal conductance under favorable water conditions was of the order of $330 \mathrm{mmol} / \mathrm{m} 2 / \mathrm{s}$. It was reduced, due to drying, in proportion to the reduction in substrate moisture content. Atlas cedar maintains gas exchange under conditions of severe water stress but can be lethal with extreme and recurrent droughts. This behavior can explain the development of the phenomenon of cedar stand decline, which is more accentuated especially with adverse ecological conditions.
\end{abstract}

\section{Introduction}

Forest tree dieback has become quite common in many regions of the world [1-5]. In Morocco, this phenomenon has been observed at the level of various natural and planted forest stands [6-8]. However, it is at the level of cedar Middle Atlas that this phenomenon was more marked [6]. However, the extent of the decline of the Atlas cedar in the Middle Atlas varied according to the ecological conditions of stands, including the type of substrate and aspects. It is rare in cedar on basalt exposed to the influences north-west, but more common on calcareous and calcareous substrates dolomitic, located on steep terrain and hot exposures [6,9]. The phenomenon of decline of the Atlas cedar has been also reported in Algeria [10]. The identification of the causes of the decline of forest stands in Morocco was subject to many controversies between researchers and managers if it would be of physiological, ecological or silvicultural origin $[8,11,12]$. But, repeated droughts associated with extremes local ecological conditions and human impact have been identified as the main causes of degradation of forest ecosystems and tree dieback, particularly in the Mediterranean region [7, 8, 13, 14]. Indeed, water stress due to prolonged and repeated droughts, physiologically weakens forest stands and makes them more vulnerable to dieback process which leads to tree mortality [1-3], $[5,8$,
$9,15,16]$. In addition, the extent of the wasting phenomenon will increase more and more relationship with the climate change outlook, which foresees a reduction in precipitation and an increase in temperature and frequency of events extremes $[3,5,12,18,19]$. The impacts of climate change would be more accentuated in the region Mediterranean and Maghrebian [21, 22].

Thereby, it seems very useful to assess the ecophysiological behavior of the Atlas cedar, more water demanding species [14], due to drought edaphic and understand their physiological temperament, especially at a young age $[23,24]$. Research work on these aspects are little developed, especially in Morocco $[8,9]$. This type of research would make it possible to determine in particular the resistance and vulnerability thresholds of the Atlas cedar to edaphic drought and to understand its physiological functioning under this constraint and to evaluate the predisposition of this noble forest species to the phenomenon of decline and even to the impacts of climate change $[1,2,8,25,26]$. The results of this work would provide useful information and indicators physiological factors likely to define drought adaptation approaches by matter of silvicultural management [27] of cedar forests and their management and also to improve reforestation practices for this important forest species. The objective assigned to this work was to study the water relations of young plants of the Atlas cedar grown under three types of substrates and subject to drought edaphic of

\footnotetext{
Corresponding author: atmane.rochdi@uit.ac.ma
} 
gradual intensity by stopping watering in order to explore the behavior Atlas cedar plants in relation to the reduction of water availability edaphic and its predisposition to the phenomenon of wasting. specific goals studies sought to (i) study the evolution of soil water reserves as a function of types of substrate, during the drying period and its impact on the relationships hydric values of cedar seedlings evaluated by measuring the water potential and conductance of stomata, (ii) determine critical thresholds of physiological behavior (water potential and stomatal conductance) of the plants against the water deficit in relation to the types of the substrate and (iii) highlight the mechanisms of adaptation to drought in young Atlas cedar plants. Plants year-old Atlas cedar were grown in three types of substrate (calcareous, basaltic and sandy) in 2.51 polyethylene containers and subjected to a deficit gradual edaphic water, by stopping continuous watering, until the appearance of signs withering away.

\section{Material and methods}

\subsection{Plant material and experimental set-up}

This study focused on 320 plants of the Atlas aged one year, produced in the forest nursery of Azrou (X = 5.239186; $\mathrm{Y}=33.428642)$ in the Middle Atlas. The seeds used for the production of the plants have were collected in the stands of Jebel Roumiat, a locality located in the region Itzer (Altitude: $2396 \mathrm{~m}$; $\mathrm{X}=-5.15266, \mathrm{Y}=$ 32.90033) located in the Middle Central Atlas. Before setting up the experiment in the school nursery National Forest Engineers ( $\mathrm{X}=-6.800470 ; \mathrm{Y}=34.041804)$, young plants were characterized, on the basis of a sample of 16 plants, by measuring a number of morphological parameters. Thus, the plants had a height average of 23.6 $\mathrm{cm}$, an average neck diameter of $3.10 \mathrm{~mm}$ and a "biomass stem / root dryness" average of 1.60. Upon receipt, the plants were transplanted into black polyethylene bags of 2.5 liters in volume, filled with one of three types of substrates used: basaltic, calcareous and sandy, at the rate of 100 plants per type of substrate. The first two substrates were sought in the Middle Atlas under natural cedar stands. The sandy substrate was taken from the forest of the Mâamora. The three culture substrates (basalt, calcareous and sand) were analyzed using Soil laboratory of the Rabat Forest Research Center. They are made up clay, silt and sand, respectively $(15.00 ; 15.40 ; 69.60 \%)$, $(10.20 ; 28.00 ; 61 ; 80 \%)$ and $(08.30 ; 03.00 ; 88.70 \%)$. The rate of clay, silt and sand are respectively superior in basaltic, calcareous and sandy substrates.

The plants planted were arranged according to an experimental device of 12 units experiments ( 3 substrates $\mathrm{x} 4$ replicates), each containing 24 plants arranged according to a complete block device, i.e. a total of 288 plants having been the subject of this experience. In addition, a batch of 10 seedlings, planted on sandy and basaltic substrates was installed near this experimental device, he played the role of Control is to evaluate the recovery speed after watering the dried plants at the end of the test dewatering. Before the application of soil drying, the plants were subject to a regular watering regime four to five times per week depending on atmospheric conditions allowing to maintain a maximum hydric state of the substrate of culture. Outside of rainy days and during hot days, plants have been watered twice a day; in the morning and in the evening after sunset.

All plants received the same amount of water. The plants were monitored daily for observe their state of health (yellowing, dryness, etc.), and eliminate the bad one's herbs as soon as they appear. The plants were fertilized three times spaced 15 days using a commercial liquid fertilizer "Algoflash $\AA$ " which contains the major elements nutrients $\mathrm{N}, \mathrm{P}$ and $\mathrm{K}$, and a supplement in trace elements. Each plant received, according to the recommendations indicated, $34 \mathrm{ml}$ after watering. The edaphic water drainage test was scheduled from April 21 to May 24. Treatment was stopped when the plants showed signs of widespread drying out but not fatal when an almost general yellowing of the seedlings needles was observed. This level of soil dryness has been assimilated to humidity at the point of temporary wilting (Hft). The drying test lasted 35 days, during this period the plants were covered, at night and on rainy days, by a canvas of plastic to prevent humidification of the substrates culture subjected to the treatment dewatering. At the end of the drying treatment edaphic, and from the day before May 25 , all cedar plants were watered at speed at capacity in the field, in order to study the water behavior plants after rehydration (recovery). During this experiment, the maximum daily temperatures varied between 18 and 36 ${ }^{\circ} \mathrm{C}$ (Fig. 1).

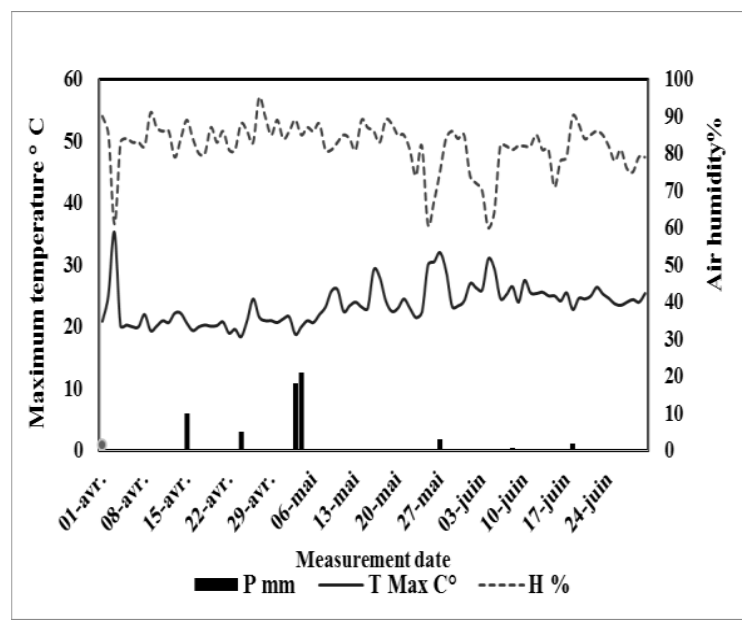

Figure 1 Variation of maximum air temperature, air humidity and precipitation during the experiment.

\subsection{Evaluation of the effect of drying on the water content of the growing medium}

The water content of the growing medium (\%) was characterized by the determination of equivalent humidity (He), estimator of humidity at field capacity, humidity at the point of temporary wilting ( $\mathrm{Hft}$ ), the available water content (TED) and the relative available water (TEDR). The equivalent humidity was determined before and at during the application of the dewatering treatment in order to take into account the settlement of the culture substrate during the period of the experiment. Humidity 
equivalent $(\mathrm{He})$ was determined after total saturation of four samples per substrate (bags filled with the same substrates used for growing seedlings of cedar). After wiping off excess water, the relative water content was determined after drying the substrates in the oven at a temperature of $105{ }^{\circ} \mathrm{C}$ for 24 hours. Moisture at the temporary wilting point (Hft) was determined, based on same procedure, when the plants showed signs of widespread drying out but not fatal. The available water content (useful reserve) (TED) was estimated by the difference between equivalent humidity and humidity at the point of temporary wilting (last measurement of the moisture content of the substrate at an apparent stress level of plants).

The Relative Available Water Content (TEDR) is the ratio between the relative water content (TER) of the growing medium, measured at each sampling, and the available water content (TED).

Measurements of the relative soil water content were performed periodically by same time as the measurements of the ecophysiological parameters since the start of the cycle water drainage and after resumption of watering (recovery period). The different parameters used to characterize the water content of the growing medium have been calculated according to the following formulas [28]:

-Relative water content: TER $(\%)=($ Fresh Weight - Dry Weight) / Dry Weight);

-Equivalent humidity (maximum water content): He (\%) = (Saturation weight - Weight dry) / dry weight;

-Moisture at the point of temporary wilting: Hft (\%) $=($ Fresh weight- Dry weight) / Dry weight)

- Available water content: TED (\%) = He (\%) - Hft (\%);

- Relative available water content (TEDR) (\%) = TER (\%) / TED (\%).

\subsection{Evaluation of the effect of drying on the water relations of the plants}

Assessment of the effect of water stress (drying out of the growing medium) on cedar plants during the period of the test was carried out, periodically, at using the measurement of a number of ecophysiological parameters: the potential predawn water before sunrise and at midday around 1:00 p.m., and the conductance maximum of the stomata (Gs) measured between 9 a.m. and 10 a.m. Potential measurements predawn $(\mathrm{Yb})$ and midday $(\Psi \mathrm{m})$ water levels were carried out throughout the water desiccation. While those of maximum stomatal conductance were carried out during the water drying cycle and after rehydration (recovery period). In addition to the predawn and midday water potential, we have determined the daily amplitude of variation of the water potential $(\Delta \Psi \mathrm{w})$ which is the difference between the predawn potential and the midday water potential. This difference made it possible to assess, indirectly and qualitatively, the size of the deficit daily hydric within the plant and that of the dynamics of gas exchange (transpiration and carbon absorption) and the critical water potential $(\Psi c)$ which indicates a higher level of water stress in the plant. This parameter was estimated using approaches to limit curves [29, 30]. It corresponds to most negative predawn water potential which correlates with the lowest daily amplitude of variation in water potential [31]. The water potential measurements were carried out by the Scholander pressure chamber (PMS, Corvallis, Oregon. USA) according to the described by [26]. The measurements of the maximum conductance of stomata (Gsmax) were performed periodically during the same days that the water potential of the plants was measured. They also took place for a period of rehydration for 18 days after resuming watering (until June 11, 2006) in order to evaluate the effect of the After effect on the resumption of the functioning of stomata after a fairly long drying period of 35 days. These measures were carried out on the same individuals. Measurements were made on sunny days between 10:00 am and 12:00 pm when the stomata are in full activity $[32,33]$ using an AP4 type porometer (Delta-t devices Ltd, UK).

The practical measurement approach has been to place the measuring clamp on needles of so as to fill the entire area of the clamp. The position of the measuring clamp must be chosen so that the needles are well exposed to the sun. But before to take the measurements, it was necessary to ensure that the device was correctly calibrated. Measures taken and the calculated parameters were automatically stored in the memory of the device. Stomatal conductance measurements were repeated 12 times each measured. Stomatal conductance, measured under water conditions and favorable climatic conditions, was retained as a maximum reference value. This value was used for the calculation of the relative maximum stomatal conductance (Gs / Gsmax).

\subsection{Data Analysis}

The data obtained were analyzed by adopting graphical approaches (curves and histograms) and analysis of variance procedures. All measurements have been repeated at least four times. The results presented as a curve or histograms, most often join the mean values framed by their standard deviations. These were produced using Excel software (Microsoft office 2010) and SPSS 12.5 software. The means were compared using the Student- Newman and Keuls (SNK), based on the smallest significant difference, using the MINITAB 13 software and SPSS 12.5. The differences due to the controlled effects were considered significant from a probability threshold of 5\%. In addition, tests of correlation between the different measured variables were attempted in order to find correlation models that can predict a parameter as a function of one or more several other parameters, in particular between the water parameters of the substrate of culture and ecophysiological parameters measured on young cedar plants in during edaphic drying. The modeling was carried out using software EXCEL (Microsoft office 2010) and SPSS 12.5. The models chosen were those who have the greatest coefficient of determination (R 2 ) is. 


\section{Results}

\subsection{Effect of drying on the moisture content of the growing medium}

The relative water content of the growing medium at the equivalent humidity $(\mathrm{He})$ varied depending on the type of substrate and the measurement date (Figure 2).

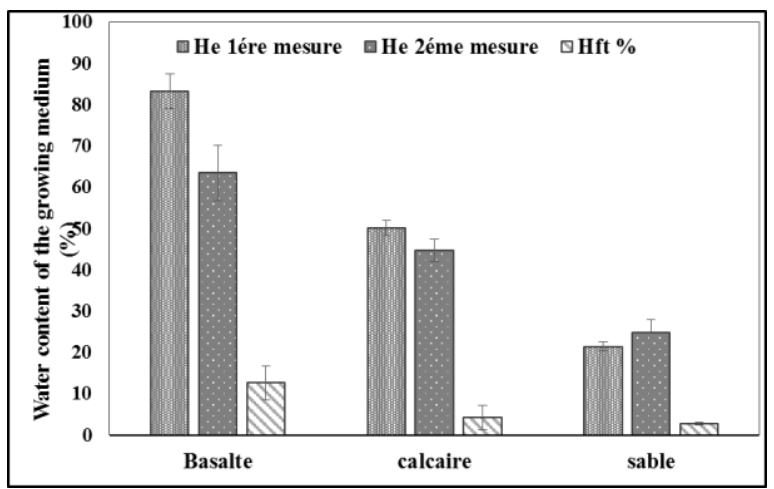

Figure 2 Equivalent humidity ( $\mathrm{He}, \%)$ of the three types of culture substrate measured at the installation of the experimental device $(01 / 20 / 2006)$ and at the end of the water desiccation test $(05 / 24 / 2006)$. The humidity at the point of temporary wilting ( $\mathrm{Hft}, \%$

It is higher for the basaltic substrate with $83.31 \%$ and $63.51 \%$, followed by calcareous substrate with $50.23 \%$ and $72 \%$, then lastly the sandy substrate with the lowest values, i.e. $21.50 \%$ and $24.97 \%$ respectively at the start and at the end of the experiment. He has decreased at the end of the experiment for basaltic and calcareous substrates. On the other hand, it experienced a small increase for the sandy substrate. These changes have had taken place under the effect of the compaction of the substrate under the effect of watering. The water content of growing medium at the temporary wilting point (Hft) was of the order of $12.71 \pm 4.07 \%, 4.27 \pm 2.92 \%$ and 2.88 $\pm 0.35 \%$ respectively for the substrate basaltic, calcareous and sandy. At these levels of substrate moisture, the majority of plants showed signs of yellowing needles and wilting generalized. The measurements of the predawn water potential, at this level of drying, have showed that the majority of plants presented very negative water potentials of the order of -36 to -38 bars. In addition, stomatal conductance was lowest, $5.6 \%$ of the maximum value. However, after rehydration (recovery), the majority of plants, that is to say $96 \%$ of the total number, have recovered and regained their greenish color.

The relative moisture content of the growing medium (TER) was significantly affected $(p<0.001)$ by the measurement date and the type of substrate (Figure 3).

She decreased during dewatering similarly for the three types of substrate, but in a manner more important for the sandy substrate, followed by the calcareous substrate and lastly the basaltic substrate that always recorded the highest values. The maximum Values of TER were observed at the start of the drying cycle, i.e. $71.92 \pm 2.29 \% ; 46.77 \pm 4.11 \% ; 29.94 \pm 3.99 \%$ respectively for basaltic substrates, calcareous and sandy (Figure 3).

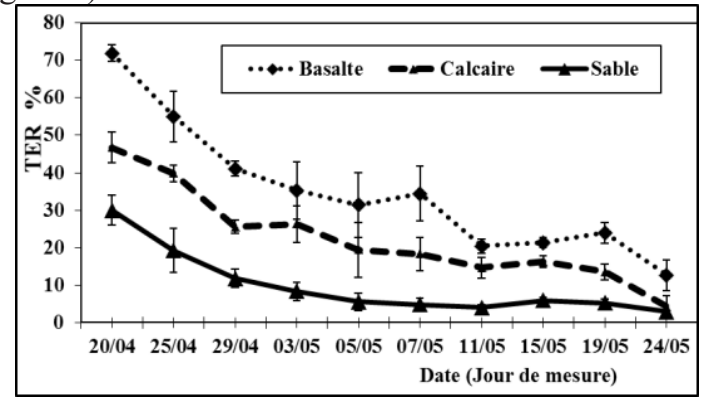

Figure 3 Changes in the relative water content (TER) of the cultivation substrate (Basalt, calcareous and sand) during the water drying cycle. Each value, with its standard deviation, is the average of eight repetitions.

The relative moisture content of the container substrates was close to the equivalent humidity. At the end of the drying cycle, after 35 days, the TER fell to values of $12.71 \pm 4.07 \% ; 4.27 \pm 2.92 \%$ and $2.88 \pm 0.35 \%$ respectively for the basaltic, calcareous and sandy substrate. Water content Relative Available (TEDR) progressed in the same way as the TER (Figure 4). His evolution during the drying cycle was also affected in a way very highly significant $(\mathrm{p}<0.001)$ by date of measurement and by type of substrate of culture. However, basaltic and calcareous substrates presented values clearly superior to those of the sandy substrate. For the three types of substrate, the decrease in TEDR was faster during the first 10 days (up to 20 April) than the rest of the drying cycle. However, from April 29, this decrease is less accentuated; it stabilizes even for the sandy substrate (Figure 3). At the end of drying cycle, the TEDR was of the order of $31.88 \pm 5.06 \% ; 15.48 \pm 6.01 \%$ and $12.84 \pm 1.58 \%$ respectively for the basaltic, calcareous and sandy substrate (Figure 4).

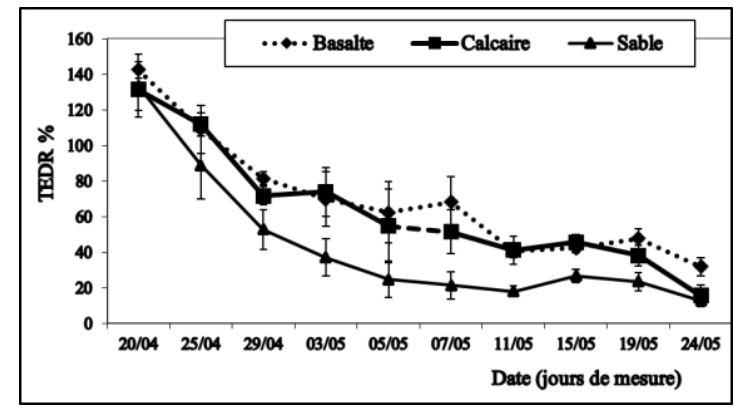

Figure 4 Evolution of the available water content relative (TEDR (\%) of the cultivation substrate ( Basalt, calcareous and sand ) during the water drying cycle. Each value, provided with its standard deviation is the average of eight repetitions.

\subsection{Effect of edaphic drying on the water status of plants}

The drying out of the growing medium adversely and significantly affected $(\mathrm{p}<0.001)$ the water status of Atlas cedar plants expressed by the potential predawn water (before sunrise) $(\Psi b)$, the midday water potential $(\Psi \mathrm{m})$ and the daily amplitude of the water potential $(\Delta \Psi)$ 
(Figures 5, 6 and 7). This effect has varied significantly ( $\mathrm{p}$ $<0.05$ ) depending on the type of culture substrate, the interaction of Measurement dates with the type of substrate has no significant effect. However, the $(\mathrm{\Psi b})$ plants on basaltic and calcareous substrates were not significantly different (Figures 5,6 and 7). At the start of drying and during the first three dates of measurement, the mean values of $\Psi \mathrm{b}$ were less negative at plant level on sandy substrate, followed by those on basaltic substrate and lastly by plants on calcareous substrate with respectively - 5.09 bar, -5.61 bar and -5.70 bar. The values less negative $\Psi \mathrm{b}$ were observed during the first ten days after drying without exceeding the level of - 10 bar. During this period, the change in water status of the plants was not too affected by the reduction in growing medium TEDR. At this level, the moisture content of the substrates at the container level was close to the equivalent water content (Figures 2 and 3). On the other hand, after 13 days of drying, the plants on sandy substrate showed more negative values of $\Psi \mathrm{b}$ compared to that of plants grown on basaltic and calcareous substrates. After 25 dewatering, the $\Psi \mathrm{b}$ of the plants decreased but in a lighter way and this in the case of the three types of substrate.

On the other hand, towards the end of the cycle, this decrease was more rapid during the last 10 days of treatment, especially in the case of plants grown on sandy and calcareous substrates than on basaltic substrate. At the end of the drying cycle edaphic, the $\Psi \mathrm{b}$ of cedar plants became more and more negative to reach very negative values, but variable depending on the type of substrate, i.e. $-32.25 \pm 3.50$ bar, $-37.38 \pm 4.03$ bar and $-39.50 \pm$ 1.00 bar respectively for plants on substrate basaltic, calcareous and sandy (Figure 5).

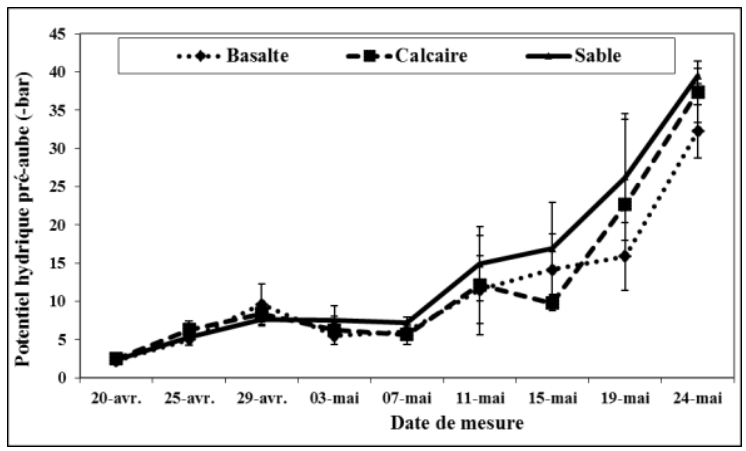

Figure 5 Evolution of the predawn water potential (-bar) of Cedrus atlantica plants during the water drying cycle for three types of substrate (Basalt, Calcareous and Sand ). Each value, with its standard deviation, is the average of four repetitions.

The relative water content of the substrates level of culture medium was very low of the order of $12.71 \pm$ $4.07 \%, 4.27 \pm 2.92 \%$ and $2.88 \pm 0.35 \%$ respectively for basaltic, calcareous and sandy substrate (Figure 2 ). Likewise, the relative available water content was of the order of $31.88 \pm 5.06 \% ; 15.48 \pm 6.01 \%$ and $12.84 \pm$ $1.58 \%$ respectively for the basaltic substrate, calcareous and sandy (figures 2, 3). That of the basaltic substrate was clearly higher, or more than double that of other growing medium. The midday water potential $(\Psi \mathrm{m})$ of the plants evolved in the same way as that of the predawn water potential (Figure 6) . This development has been affected significantly $(p<0.001)$ by reducing the water content of the growing medium and the measurement date. The interaction "measurement date x culture substrate" was also significant $(\mathrm{p}<0.05)$. On average the values of $\Psi \mathrm{m}$ of the plants were significantly more negative on sandy substrate than on calcareous substrate and basaltic. Plants on this latter substrate showed the least negative values (Figure 6).

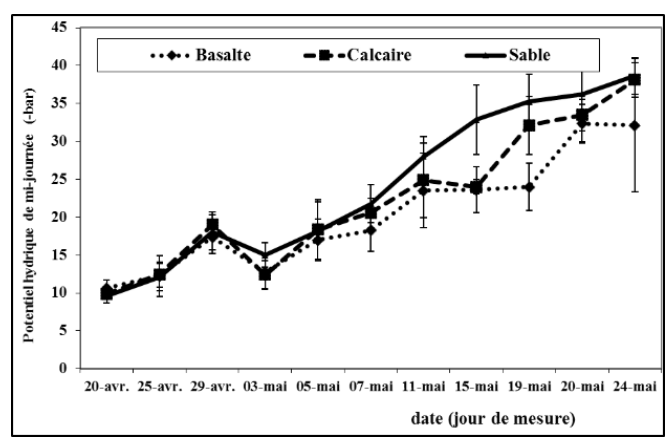

Figure 6 Evolution of the midday water potential (-bar) of Cedrus atlantica plants during the water drying cycle for three types of substrate (Basalt, Calcareous and Sand ). Each value, with its standard deviation, is the average of four repetitions.

In general, the $\Psi \mathrm{m}$ values of the plants were more negative than those $\Psi b$, regardless of the type of growing medium. The values of $\Psi \mathrm{m}$ have varied between - 09 and -25 bar during the first three weeks of drying out, but after on May 15 the $\Psi \mathrm{m}$ of the plants became more negative to reach values which vary between - 25 and - 40 bar depending on the type of growing medium. At the end of the cycle dewatering, the $\Psi \mathrm{m}$ reached more negative values, ie - 32.13 bar; - 38, 13bar and 38, 63 bar respectively at plant level on basaltic, calcareous and sandy, very close to the values of $\Psi \mathrm{b}$, i.e. - $32.25 \pm 3.50$ bar, $-37.38 \pm 4.03$ bar and $-39.50 \pm 1.00$ bar respectively at the level of the plants on basaltic, calcareous and sandy (Figures 5 and 6). The maximum amplitude of the daily variation in the water potential of the plants $(\Delta \Psi)$ which expresses the absolute value of the difference between the midday potential and that of predawn evolved significantly ( $\mathrm{p}<0.01)$ during the drying cycle edaphic. But the interaction of culture substrate and date was not significant (Figure 7). The daily magnitude of the water potential $\Delta \Psi$ varied during the period of experimentation between 0 and 25 bar. The lowest values (10 to 5 bar) were observed at the start and at the end of the water drying cycle. While the values higher are in the middle of the drying cycle, ie 10 to 15 bar. The last values at the end of the drying cycle were lower than 5 bar . However, those of plants on basaltic substrate were higher compared to those of developed plants grown on calcareous and sandy substrates (Figure 7). The lowest values of $\Delta \Psi$ were observed at pre-dawn water potentials more negative than - 35 bar (Figures 5 and 7). Estimation of critical water potential $(\Psi \mathrm{c})$ which corresponding to the predawn water potential correlated to a very low $\Delta \Psi$ allowed note that this parameter varies slightly depending on the type of growing medium. 
Thus, the estimated $\Psi \mathrm{c}$ was $-39,-36$ and -38 bar respectively for the plants on basaltic, calcareous and sandy substrates.

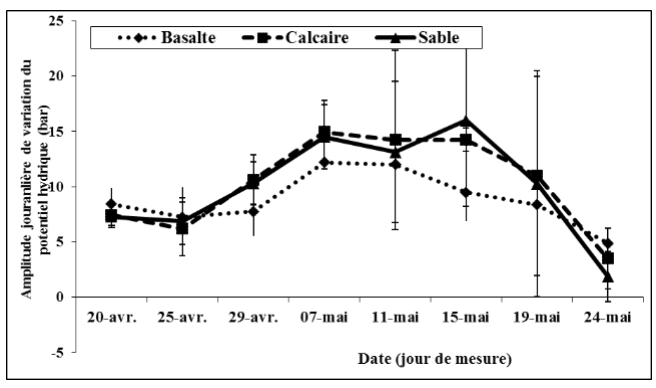

Figure 7 Evolution of the daily amplitude of variation in water potential (bar) of Cedrus atlantica plants during the water drying cycle for three types of substrate (Basalt, Calcareous and Sand ). Each value, with its standard deviation, is the average of four

\subsection{Effect of drying on maximum conductance of plant stomata}

Before the application of the soil dryness test, the maximum conductance of cedar plant stomata was not significantly affected by substrate type culture (Figure 8 ). The values of the maximum stomatal conductance (Gsmax) have varied between $305.1 \pm 140 \mathrm{mmol} / \mathrm{m} 2$ / $\mathrm{s}, 389 \pm 101 \mathrm{mmol} / \mathrm{m} 2 / \mathrm{s}$ and $307 \pm 107 \mathrm{mmol} / \mathrm{m} 2$ / $\mathrm{s}$, respectively on basaltic, calcareous and sandy substrate (Figure 8). Conductance average maximum of plants, all substrates combined, and under water conditions favorable was of the order of $330 \mathrm{mmol} / \mathrm{m} 2$ / s (Figure 8). But from the application of cycle of edaphic drying out, the Gsmax decreased in a very significant ( $p$ $<0.001$ ). The effect of the substrate and the effect of its interaction with the date of measurement were significant $(p<0.05)$. The negative effect of dewatering on stomatal functioning of the plants was observed even during the recovery (16 days), after resuming daily watering (Figures 8 and 9$)$.

During the first five days of drying out, the Gsmax decreased slightly, or $92.4 \%$ of the average maximum value. We recorded values close to Gsmax, or $270.1 \pm$ $64.8 \mathrm{mmol} / \mathrm{m} 2 / \mathrm{s} ; 328.2 \pm 119.5 \mathrm{mmol} / \mathrm{m} 2 / \mathrm{s}$ and $314.7 \pm 101.6 \mathrm{mmol} / \mathrm{m} 2 / \mathrm{s}$, respectively on basaltic, calcareous and sandy substrate. But from April 25 until May 5, after 5 days of drying out, this decrease was very rapid for all plants on the three types of substrate, with values of $115.8 \pm 35.2 \mathrm{mmol} / \mathrm{m} 2 / \mathrm{s} ; 98.4 \pm 50.5 \mathrm{mmol}$ / $\mathrm{m} 2$ / s and $90.6 \pm 44.7 \mathrm{mmol} / \mathrm{m} 2$ / s respectively on basaltic, calcareous and sandy substrates (Figure 8 ). This reduction was, on average, $102 \pm 44 \mathrm{mmol} / \mathrm{m} 2 / \mathrm{s}$, or $30 \%$ of the average maximum value $(330 \mathrm{mmol} / \mathrm{m} 2 / \mathrm{s})$ (Table 1). The maximum conductance of the stomata increased slightly around the 7 May, it then resumed its decline gradually to reach values very low on the last day of water drying (May 24), i.e. $19.3 \pm 11.2 \mathrm{mmol} / \mathrm{m} 2 / \mathrm{s}$, $25.6 \pm 24.7 \mathrm{mmol} / \mathrm{m} 2 / \mathrm{s}$ and $10.2 \pm 5.3 \mathrm{mmol} / \mathrm{m} 2 / \mathrm{s}$, respectively on basaltic substrates, calcareous and sandy. On average, the Gsmax was $18 \pm 16.75 \mathrm{mmol} /$ $\mathrm{m} 2 / \mathrm{s}$, i.e. $5.6 \%$ of the maximum average value calculated on April 20 (330 mmol / m 2/ s) (Table, 1, Figures 8 and 9).

During the last day of water drying, after 35 days of drying, the young cedar plants have shown advanced signs of dieback, including for those on sandy substrate which presented obvious drying aspects needles and branches. So the growth stopped, the needles became pungent and leathery, their color has turned to yellowing. On the contrary, the plants on basalt have not experienced any drying out of their branches, barely a few needles older days have changed color. Some plants on calcareous have experienced certain drying out of branches, but less pronounced than those of plants on substrate sandy. It has also been noticed that drying out begins from terminal buds of Atlas cedar plants. But at the end of the drying test edaphic, the majority of plants have generally formed scales on their bud's terminal and axillary, which indicated the cessation of growth in length.

After rehydration of the plants, the conductance of the stomata did not return to the level recorded before the application of soil dewatering (Figures 8 and 9). The functioning of the stomata during the rehydration period was affected very highly significant $(p<0.001)$ by the effect of edaphic drying.

During this period, the conductance of the stomata of seedlings undergoes drying out. and the control plants, maintained at a normal watering regime since the start of experimentation, have maintained a similar trend. But, stressed plants have had a significantly lower maximum stomatal conductance $(p<0.01)$ than that of plants maintained under a normal watering regime. This difference is dimmed after the twelfth day of watering: i.e. 7 days after rehydration (Figure 9), after which the Gsmax values stabilized, for stressed plants and those maintained under a normal watering regime (Figure 8). Control plants and rehydrated showed towards the end of the rehydration phase a conductance stomatal respectively $116.0 \pm 32.7$ $\mathrm{mmol} / \mathrm{m} 2 / \mathrm{s}$ and $89.6 \pm 30.5 \mathrm{mmol} / \mathrm{m} 2$ / s, i.e. $93 \%$ and $98 \%$ of the maximum values observed during this period, at the end of the experiment around June 11, i.e. 17 days after rehydration (Figure 8).

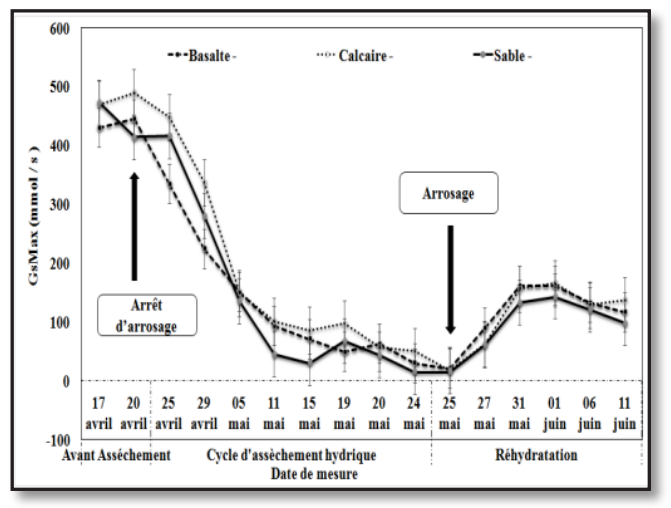

Figure 8 Evolution of the maximum stomatal conductance of the plants Atlas cedar depending on the type of growing medium ( basalt, calcareous and sand), during the water drying cycle and during rehydration (recovery). Each value, with its standard deviation. 


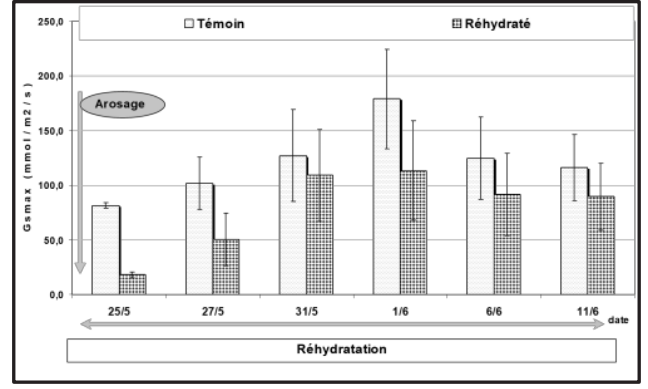

Figure 9 Maximum stomatal conductance between control maintained regular watering seedlings and that of are watered plants after the drying cycle. Each value, with its standard deviation, is the average of four repetitions.

\subsection{Relationship between ecophysiological parameters and the moisture content of the substrate}

The relationship between the predawn water potential and the relative available water content (TEDR) varied depending on the type of substrate (Table 1). But overall the potential predawn water content of cedar plants was correlated with the relative available water content (TEDR) of the culture substrates (Table 1). The coefficient of determination exceeds 0.60 which shows that the relationship is relatively strong enough. For all types of substrate, the predawn water potential of the plants becomes more negative when the in soil water decreases, but this relation tends exponentially. Conductance maximum stomatal was also correlated with relative available water content (TEDR) and with the predawn and midday water potential. But the relationship with the midday water potential was higher $(\mathrm{R} 2=0.8441)($ Table 2$)$.

Table 1 Relationship between the predawn water potential ( $\Psi$ b ) (bar) of the plants of Atlas cedar and the relative available water content (TEDR) of the growing medium .

\begin{tabular}{|c|c|c|}
\hline $\begin{array}{c}\text { Substrate } \\
\text { type }\end{array}$ & Model & R 2 ) \\
\hline Basalt & $\Psi b=1528$ TEDR $-1.2465(6)$ & 0.76 \\
\hline Calcareous & $\Psi b=1258.5$ TEDR $-1.2211(7)$ & 0.75 \\
\hline Sand & $\Psi b=238.73$ TEDR $-0.8968(8)$ & 0.66 \\
\hline $\begin{array}{c}\text { All } \\
\text { substrates } \\
\text { combined }\end{array}$ & $\Psi b=23.795 e-(0.0151$ TEDR) (9) & 0.64 \\
\hline
\end{tabular}

Table 2. Regression equations between, on the one hand, the maximum stomatal conductance ( $\mathrm{mmol} / \mathrm{m} 2$. / S) and the predawn water potential (bar) $(\Psi \mathrm{b})$, the midday water potential (bar) ( $\Psi \mathrm{m})$ Atlas cedar plants and the relative available water content of the growing medium for any substrate combined.

\begin{tabular}{|l|l|c|c|}
\hline $\begin{array}{l}\text { Regression } \\
\text { equation }\end{array}$ & \multicolumn{2}{|l}{$\begin{array}{l}\text { Parameters } \\
\text { equations }\end{array}$} & \multicolumn{1}{c|}{ of regression } \\
\cline { 2 - 4 } & $\mathbf{a}$ & $\mathrm{b}$ & $\mathrm{R}^{2}$ \\
\hline Gsmax $=\mathrm{a} * \Psi$ b & 1171.1 & -1.1552 & 0.69 \\
\hline $\begin{array}{l}\text { Gsmax } \\
\mathbf{a} \exp (\mathbf{b} \Psi \mathrm{m})\end{array}$ & $\mathbf{1 0 5 7}$ & -0.115 & 0.84 \\
\hline
\end{tabular}

\section{Discussion}

\subsection{Effect of edaphic dewatering on water potential parameters}

The water potential parameters $(\Psi b, \Psi m, \Delta \Psi)$ of the Atlas cedar plants have were significantly $(\mathrm{p}<0.001)$ affected by the drying out of the growing medium. However, the effect varied significantly $(p<0.05)$ depending on the type of growing medium and the date of measure. The effect was more intense with the length of the drying time and more marked in plants on sandy substrate. Under favorable water conditions, the values of the pre-dawn potential were of the order of $-2.20 ;-2.45$ and -2.35 bar respectively in cedar plants on basaltic, calcareous and sandy substrates. These values are close to those observed on cedar plants planted in a natural environment on a soil well supplied with water [31] whose water potential predawn was of the order of -2 bars to -4 bars. These same authors have cited other similar values of the order of $4.2 ;-4.9 ;-2 ;-2 ;-1$ and -2 bar measured on other species which have been subjected to favorable hydric conditions respectively Picea glauca, Larix laricina, Abies procera, Abies amabilis, Pinus contorta and Pinus resinosa.

Under very favorable water conditions, the water status of cedar plants changed closer to the state of turgor $(\mathrm{TER}=100 \%)$. But, at the end of the drying cycle water, the predawn water potential of the plants reached more negative values of the order of $-32.25 ;-37$, and -39.5 bar respectively on basaltic, calcareous and sandy. At this level, the relative water content of the growing medium was very low by around $11.08 \% ; 4.08 \%$ and $2.25 \%$ respectively on basaltic, calcareous and sandy. Likewise, the relative available content (TEDR) was of the order of $31.88 \% ; 15.48 \%$ and $12.84 \%$ respectively for the basaltic, calcareous and sandy substrate.

The hydric state of the sandy soil was more deficient. In a natural environment and under moderate drought conditions, we measured on Atlas cedar trees of the water potentials of around -29 bars in France [24] and in Morocco [9]. These values are clearly less negative than those observed in the case of Mediterranean oak species, Q. suber and Q. coccifera, more adapted to drought conditions and where the predawn water potential can reach, under conditions of severe edaphic drought, more negative values respectively -46.5 and -38.5 bar [34].

The relationship between the variation of the predawn water potential and the reduction in the content in soil water has been reported in various ecophysiological research studies $[9,26,28,31]$. A reduction in the predawn water potential (more negative) indicates a reduction in the water content of the soil. The water potential predawn seedlings can be used to predict soil moisture content $[24,31,35]$.

The water potential of midday plants depends both on the water content of the soil and the evapotranspiratory demand of the air, which influences in particular the dynamics the functioning of the stomata (gas exchange). During the drying cycle hydric, the midday 
potential values of cedar plants were affected very highly significant by the measurement dates (drying time) and by the type of substrate $(p<0.001)$. At the start of the drying cycle, when plants have been well supplied with water, the values of $\Psi \mathrm{m}$ were of the order of -10.63 ; -9.89 bars and -9.63 bar respectively in plants on basaltic, calcareous and sandy substrates. These values show climatic conditions and in particular temperatures, during the end of April and the beginning of May, were not elevated (Figure 1). These values are close to those observed on mature trees in the Middle Atlas [9]. In the natural environment, [31] have recorded on irrigated trees values of the order of -23.5 bar on Pseudotsuga menziesii , -18 bar on Abies nordmanniana , -13.5 bar on Picea abies , 11.5 bar on Pinus nigra and -9 bar on Pinus sylvestris. In contrast, under drought conditions moderate, They observed values close to -20 bar on Picea abies , -17 bar on Pinus nigra and -16 bar on Pinus sylvestris .

At the end of the drying cycle, the cedar plants exhibited negative of $\Psi \mathrm{m}$, or $-32.13 ;-38.13$ and - 38.63 bar respectively on substrates basaltic, calcareous and sandy. In a natural environment, and under drought conditions accentuated, the Atlas cedar trees recorded very negative $\Psi \mathrm{m}$ values of the order of -39 bar [24]. The same authors measured negative values of $-38,-37$ bar on Quercus ilex and Pinus halepensis trees, which are species more dependent on drier stations on the edaphic level.

Cedar plants exhibited high values of maximum amplitude between 12.20 and 14.95 bar in the middle of the soil drying cycle, during the period from 03 to May 20 . These values are close to those observed on mature trees in the Middle Atlas and during the period when the water balance of the soil is favorable [9]. But at the start and end of the drying cycle, the $\Delta \Psi$ values were the lower in the order of $4.88 ; 3.50$ and 1.88 bar respectively on basaltic substrates, calcareous and sandy towards the end of the drying cycle. At the start of the cycle, from April 20 to May 03, the climatic conditions were more or less unstable characterized by a some spring freshness (cloudy days and lower temperature), which would limit the opening of the stomata [9]. But from 05 May the days of measurement were clear and sunny, the stomata had a optimal operation which has favored gas exchange and water losses through sweating [32]. Towards the end of the drying cycle, the values $\Delta \Psi$ were the weakest. At that time, the measurement days were clear and well sunny. Nevertheless, this time, it is the water content of the growing medium at the level of the containers which has been a limiting factor in stomatal opening. As things progress as the drying out of the soil increases, the transpiration decreases, the $\Delta \Psi$ decreases and tends towards zero which indicates that the stomata are closed [9]. These findings were observed on Atlas cedar trees in a natural environment $[31,9]$. The maximum amplitude of change in water potential, reflects the intensity of the opening of the stomata and indicates indirectly the dynamics of gas exchange $[9,32]$. The representation of the pre-dawn potential as a function of the maximum amplitude of variation of the water potential made it possible to estimate the critical water potential of cedar plants, which corresponds to a value of the predawn water potential for a $\Delta \Psi$ low (less than 4 bars according to [31] and where the closure of stomata is almost total. The estimated critical water potential values were the order of $-39,-36$ and -38 bar respectively for plants on basaltic substrates, calcareous and sandy. These values were reached at relative water contents of the order of $13.44 \%, 9.04 \%$ and $2.92 \%$ respectively at the level of basaltic, calcareous and sandy. The estimated values of $\Psi \mathrm{c}$ are relatively more negative than those reported for Atlas cedar in other studies $[9,24,31]$; and for other species forestry -34 bar, -34 bar , -33 bar, -17 bar, -16.5 bar and -16 bar respectively for Quercus ilex, Acer opulifolium, Quercus pubescens, Pinus pinaster, Pinus uncinata, and Pinus sylvestris [24].

\subsection{Maximum stomatal conductance}

The maximum stomatal conductance measured under very favorable water conditions, before the onset of soil drying, was on average, for the three types of substrate, $330 \mathrm{mmol} / \mathrm{m} 2 / \mathrm{s}$. This value was obtained for a potential pre-dawn of the order of -2.33 bar and a maximum relative available water content at level of very saturated substrates. The maximum conductance of the stomata measured under of unrestricted water conditions is close to values reported for other Mediterranean forest species, under similar conditions, $376 \mathrm{mmol} / \mathrm{m} 2$ / s for Quecus ilex [36], $254 \mathrm{mmol} / \mathrm{m} 2 / \mathrm{s}$ and $370 \mathrm{mmol} / \mathrm{m} 2 / \mathrm{s}$ for Quercus suber [36, 37]. [34] found higher values varying between 400 and $600 \mathrm{mmol} / \mathrm{m} \mathrm{2} / \mathrm{s}$ for plants of Q. faginea , Q. suber and Q. coccifera . However, stopping watering affected the stomata to close and reduction of gas exchange. As the water content of the substrates in the containers decreases, the water potential in the plants becomes more negative and therefore gas exchange through the stomata becomes more reduced. The stomatal conductance gradually decreased and the first effects on the stomatal opening appeared from the start. This type of behavior is very common in many forest species [38]. Nevertheless, the exchanges gas in cedar plants remained active, albeit reduced, to levels critical water potential of the order of -39 bars, -36 bars and -38 bar respectively for plants on basaltic, calcareous and sandy substrates. The continuation of gas exchange, in the Atlas cedar, continues even at predawn water potential more negative down to -50 bar $[23,39]$. But the cessation of height growth in cedar plants has been observed at less negative water potential around -21 bars $[23,31]$. The physiological processes underlying the growth, meresis and auxins, are the most affected by the water deficit, which affects cell turgor [40], as well as respiration [41]. Continuation of gas exchange under conditions of increased edaphic drought is an index of drought tolerance [31, 35, 39, 42]. This type of behavior makes it possible to classify the cedar of Atlas among anisohydric species [5], which manage to maintain their stomata open longer even if their water status becomes more deficient, which gives them a more sustained photosynthetic activity even at low water potential. This ability allows the Atlas cedar to maintain a active photosynthesis under drought conditions and no 
straining mechanisms biochemicals concerned with osmotic adjustment that much later than other conifers. This makes it possible to continue the synthesis of assimilates necessary for survival under extreme water stress conditions [43], and this to maintain active breathing which is essential for survival of trees during a prolonged period of drought. Indeed, the energy produced is used in various physiological processes that prevent the dehydration, such as maintaining hydraulic permeability, turgor of phloem cells and the repair of embolized vessels [41].

However, species which maintain their gas exchange for a very long time, under drought conditions that persist, run the risk of too much dehydration tissues which may ultimately alter the photosynthetic efficiency of the tree, and which may go until the tree dies [2, 3, 18, 39]. This type of physiological process would probably be at the origin of the phenomenon of the decline of the Atlas cedar $[8,9,44]$. Mortality can occur including when the breathing process is severely affected. Which would not allow the plant to maintain the production of the energy necessary to maintain the viability of structures cellular [41]. The functioning of the stomata after rehydration was negatively affected by the water stress. Its effect lasted several days after the drying out, but we noticed that the Atlas cedar is a species that easily recovers after edaphic desiccation. However, the speed of recovery depends largely part of the severity of stress. [23] and [39] report that Atlas cedar plants subjected to drought conditions for a period of entire year have regained much of their delay in height growth when they are subjected to humid conditions on the following year. The effects of edaphic dewatering were most accentuated on plants grown on the calcareous and sandy substrate. Plants on basaltic substrate were less affected by the edaphic water deficit than the others. The basaltic substrate, due to its physicochemical characteristics, maintains more humidity than other substrates.

The positive effect of this substrate on the behavior of Atlas cedar has been reported in numerous studies [9, 45].

\subsection{Relationship between the ecophysiological parameters and the water state of the substrate of culture}

The water potential is correlated with the water state of the growing medium expressed by the relative water content available. The maximum conductance of the stomata of the plants is also correlated with the water state of the substrate at the water potential in particular the midday water potential. This type of relationship has been observed in many forest species, such as carob [38], Mediterranean oaks caducifoliates and sclerophylls [36], Eucalyptus globulus and in other oak species [4648]. The reduction in the water content of the substrate causes a reduction in the conductance of stomata and negatively affects the water status, the water potential of which becomes more and more negative with increasing intensity of drying. This behavior is widely documented in Mediterranean forest species [46, 47]. Measurements of the water potential of the plants and the conductance of the stomata allows you to learn about the water state of the substrate and the relationship between plants and the climatic and water conditions of the development sites forest $[46,32,48]$, which would allow the development of models to predict the behavior of species forest under the environmental conditions of their development.

\section{Conclusion}

Atlas cedar plants, subjected to a gradual and severe edaphic drought to the end of the dewatering test, showed drought tolerance behavior expressed by the continuation of their gas exchanges up to a critical water potential fairly negative of the order of -39 bars, -36 bars and -38 bars respectively on substrates basaltic, calcareous and sandy. The corresponding relative water contents recorded at the level of the culture substrate were very low: $12.71 \% ; 4.27 \%$ and $2.88 \%$ on basaltic, calcareous and sandy substrate. This critical predawn water potential level corresponds to the threshold below which the survival of the plants is at stake determined are consistent with values published by other researchers. These results allow to qualify, the provenance (Jbel Roumiat ) of the young plants of the cedar of the Atlas, used in this work, of drought tolerant provenance, as the plants keep their stomata open longer, which gives them activity more sustained photosynthesis at low water potential. But behavior that is beneficial for Atlas cedar adaptation to variations in fairly frequent soil water conditions in a Mediterranean climate, and also threatening to its survival when the water deficit extends beyond the levels determined reviews and lasts longer.

Atlas cedar is not a water conserving species as in the case of firs and some pines $[28,39,42]$. She maintains gas exchange under water stress conditions. This behavior physiological can explain its predisposition to the phenomenon of wasting under the natural conditions where the water balance of the soil is certainly often in deficit especially when ecological conditions are limited (exposed slopes, soils shallow, highly filtering, etc.) [2, 5, 9]. Indeed, the stands of cedar of the Atlas were subject these years to severe and repeated droughts (exhaustion phenomenon), including the effects are amplified by the human impact (in particular its impact on the soil); and also by the absence of intensive silviculture which should maintain the stands of cedar in a state of equilibrium with the ecological conditions of the stations (reduction of surplus material). This last aspect has been highlighted by recent work carried out on the assessment of dieback in natural cedar stands using silvicultural and ecological approaches [6].

As recommendations, we propose to further research ecophysiological studies on the Atlas cedar, under natural conditions, to assess the water balance within cedar stands and in different situations edaphic, topographic, structure and density, and the effects of treatments silvicultural (thinning in particular) on water relations and gas exchanges cedar trees and their balance with site conditions [9]. The results would be of great importance for the evaluation of the vulnerability of the Atlas cedar and its ability to adapt 
to the effects of change climate $([3,18,20]$. As well, further research is needed to improve the quality of Atlas cedar plants produced in forest nurseries and the techniques of their plantations, which would improve the success of plantations in the field when natural regeneration is absent or rare [49]. It would be necessary to produce seedlings in the nursery whose characteristics would be in adequacy with the ecological specificities of the sites of their plantation. Adaptations must be focused in particular on the root system which must be sufficiently developed to allow newly planted plants to exploit reserves available in the soil [9].

\section{References}

1. Adams H.D., Macalady A.K., Breshears D.D., Allen C.D., Stephenson N.L., Saleska S.R., Huxman T.E. \& McDowell N.G., 2010. Climate-induced tree mortality: Earth system consequences. EOS, 91, pp: 53-54.

2. Allen C.D., Macalady A.K, Chenchouni H., Bachelet D., McDowell N., Vennetier f M., Kitzberger T., Rigling A., Breshears D.D., Hogg E.H., Gonzalez P., Fensham R., Zhang Z., Castro J., Demidova N., Lim J.-H., Allard G., Running S.W., Semerci A. \& Cobb N., 2010. A global overview of drought and heatinduced tree mortality reveals emerging climate change risks for forests. For. Ecol. Manage. 259, pp: 660-684.

3. Choat B., Jansen, S., Brodribb T.J., Cochard H., Delzon S., Bhaskar R., Bucci S.J., Field T.S, Gleason S.M., Hacke H.G., Jacobsen A.L., Lens F., Maherali H., Martı'nez-Vilalta J., Mayr S., Mencuccini M., Mitchell P.J., Nardini A., Pittermann J., Pratt, R.B., Sperry, J.S., Westoby, M., Wright, I.J. \& Amy E.Z. 2012. Global convergence in the vulnerability of forests to drought. Nature, $49: 752-755$.

4. Le Meignen P., Micas L. 2008. Bilan des dépérissements forestiers dans les Alpes-de- HauteProvence, Forêt Méditerranéenne, 29[2], pp : 177182.

5. McDowell, N., Oockman, W.T., Allen, C.D., Breshears, D.D., Cobb, N., Kolb, T., Plaut, J., Sperry, J., West, A., WilliamsOn, D.G. \& Yepez, E.A., 2008. Mechanisms of plant survival and mortality during drought: why do some plants survive while others succumb to drought?. New Phytologist, 178 , pp: 719-739.

6. Anonyme 2007 Etude des causes de dépérissement de la cédraie du Moyen Atlas. Projet «Etude des causes du dépérissement de la cédraie du Moyen Atlas » élaboré par le Haut-Commissariat aux Eaux et Forêts et à la Lutte Contre la Désertification (HCEFLCD), avec l'assistance de la FAO, dans le cadre général de la «Convention FAO/UTF/MOR/028/MOR. Appui à la mise en œuvre du programme forestier national ». HCEFLCD, Rabat.

7. Rhanem M. 2011. Aridification du climat régional et remontée de la limite inférieure du cèdre de l'Atlas
(Cedrus atlantica Manetti) aux confins de la plaine de Midelt (Maroc). Physio-Géo-Géographie Physique et Environnement, 5, pp :143-165.

8. Zine El Abidine A. 2003. Le dépérissement des forêts au Maroc : analyse et stratégies de lutte. Sécheresse, $14[4]:$ p 18-209.

9. Zine El Abidine A., Lamhamedi M, Aadel T. 2013 : Relations hydriques des arbres sains et dépérissants de Cedrus atlantica M. au Moyen Atlas Tabulaire au Maroc. Geo-Eco-Trop., 2013, 37, 2 : 157-176.

10. Kherchouche D., Kalla M., Gutierrez E., Briki A., Hamchi A. 2013. La sécheresse et le dépérissement du cèdre de l'Atlas (Cedrus atlantica Manetti) dans le massif du Belezma (Algerie). Sécheresse, 24, pp :129-37.

11. ET-Tobi, M. 2006. Approche multidimensionnelle des relations "Etat sanitaire- Station - Sylviculture" pour l'étude du dépérissement des cédraies au moyen Atlas en vue d'élaborer un modèle sylvicole de prévention phytosanitaire. Thèse présentée à l'institut agronomique et vétérinaire Hassan II2. 174 p. + Annexes

12. Gillian A., 2005. Problématique de dépérissement de la cédraie du moyen Atlas, Exposé présenté à l'Atelier de la commission du projet chargé de diagnostic des facteurs de dépérissement de la cédraie du moyen Atlas. DREF Moyen Atlas à Méknes.

13. Barbero M., Bonin G., Loisel R. \& Quezel P. Changes and disturbances of forest ecosystems caused by human activities in the western part of the mediterranean basin. Vegetatio 1990 ; 87, pp : 151173.

14. Benabid A. 2000. Flore et écosystèmes du Maroc. Evaluation et préservation de la biodiversité. Editions Ibis Press Paris. 2000 ; 359p.

15. Brydges T., P. Hall, et O. Loucks 2000. La santé et le dépérissement des forets. Rapport de l'atelier et de la visite sur le terrain - Muskoka, $25 \mathrm{p}$.

16. Manion P.D. \& Lachance D. 1992. Forest decline concepts. An overview. In Forest decline concepts, editet by Manion and D. Lachance. PDS Press, Minnesota, pp: 181-190.

17. Anonyme, 2014. Politique du changement climatique au Maroc. Ministère délégué auprès du Ministre de l'Energie, des Mines, de l'Eau et de l'Environnement, chargé de l'Environnement 35p.

18. Aussenac G., Bonneau M., Landmann G., Troy J.P. 1996. Evolution des sols et changements globaux : Deux enjeux majeurs pour la durabilité des écosystèmes forestiers. Rev. For. Fr., XIVIII (NS), pp: 7588.

19. Ciesla M.W., 1997. Le Changement Climatique, les Forêts et l'Aménagement Forestier : Aspects Généraux. Forestier (protection des forêts) Division des ressources forestières (Etude FAO Forêts - 126). http://www.fao.org/docrep/v5240f/v5240f00.htm\#C ontents 
20. Demarteau M, François L., Cheddadi R. et Roche E. 2007. Réponses de Cedrus atlantica aux changements climatiques passés et futurs. Geo-Eco-Trop, 31 :105146.

21. 42. Taabni M. et El Jihad M-D., 2012.Eau et changement climatique au Maghreb : quelles stratégies d'adaptation? Les Cahiers d'Outre-Mer, 260, pp : 493-518.

22. Vennetier M., Vila B., Liang E-Y ., Guibal F., Ripert CH. Et Chandioux O., 2005. Impact du changement climatique sur la productivité forestière et le déplacement d'une limite bioclimatique en région méditerranéenne française. Ingénieries, 44, pp : 4961.

23. Aussenac G. \& Finkelstein D. 1983. Influence de la sécheresse sur la croissance et la photosynthèse du Cèdre. Ann. Sci. For. 39, pp : 41-62.

24. Aussenac G. \& Valette J.C. 1982. Comportement hydrique estivale de Cedrus atlantica Manetti, Quercus ilex L. et Quercus pubescens Willd. et de divers pins dans le Mont Ventoux. Ann. Sci. For. 39, pp: 41-62.

25. Newton R.J., Funkhouser E.A., Fong F. \& Tauer C.G. 1991. Molecular and physiological genetics of drought tolerance in forest species. For. Ecol. Manag. ; 43: 225-250.

26. Zine El Abidine A., Bernier P.Y. et Plamondon A.P. 1997. Ecophysiologie de l'épinette noire (Picea mariana) en relation avec sa tolérance au stress hydrique. Ann. Rech. For. Au Maroc, 30 , pp:145166.

27. Aussenac G. 2000. Interactions between forests stands and microclimate: Ecophysiological aspects and consequences for sylviculture. Ann. For. Sci. 57, pp : 287-301.

28. Zine El Abidine A., Bouderrah M., Moustahssen A., Lamhamedi M.S. 2016a. Relations hydriques et croissance de plants soumis à un déficit hydrique édaphique graduel - Cas du cèdre de l'Atlas, du pin maritime de montagne et du cyprès de l'Atlas. Forêt Méditerranéenne, iv, pp : 327-342.

29. Chambers J.L., Hinckley T.M., Cox G.S., Metcalf C.L., Aslin R.G., 1985. Boundary-line analysis and models of leaf conductance for four oak-hickory forest species. Forest Sciences, 31[2], pp. 437-450.

30. Webb, R.A., 1972. Use of the boundary line in the analysis of biological data. J. hort. Sci. 47, pp: $309-$ 319.

31. 7. Aussenac et Granier 1978, Quelques résultats de cinétiques journalières du potentiel de sève chez les arbres forestiers. Ann. Scie. For. 35. 19-32.

32. Hinckley T.M., Lassoie J.P., Running S.W. 1978. Temporal and spatial variation in the water status of forest trees, Forest Science, Mono, 20, pp : 1-72.

33. Zine El Abidine A., Bernier P.Y. et Plamondon A.P. 1993. Ecophysiologie de l'épinette noire (Picea mariana) en relation avec sa tolérance au stress hydrique. Ann. Rech. For. Au Maroc ; 30 :145-166.
34. Ksontini M., Louguet P., Laray D., Rejeb M.N. 1998. Comparaison des effets de la contrainte hydrique sur la croissance, la conductance stomatique et la photosynthèse de jeunes plants de chênes méditerranéens (Q. suber, Q. faginea, Q. coccifera) en Tunisie, Annales des Sciences Forestières, 55 [4], pp :477-495.

35. Aussenac G. 1993. Déficits hydriques et croissance des arbres forestiers. Forêt Entreprise, 89, pp : 40-47.

36. Acherar M., Rambal S. , Lepart J. 1991. Evolution du potentiel hydrique foliaire et de la conductance stomatique de quatre chênes méditerranéens lors d'une période de desséchement. Ann.Sci.For. 48.pp : 561-573.

37. TENHUMEN J., BEYSCHLAG W., LANGE O. L., HARLEY D. C. 1987. Changes during summer drought in leaf $\mathrm{CO} 2$ uptake rates of macchia shrubs growing in Portugal: Limitations due to photo synthetic capacity carboxylation effeciency, and stomatal conductance. - In: TENHUMEN J. D., CATARINO F. M., LANGE O. L \& OECHEL W. C. (Eds.), Plant response to stress. Functional analysis in Mediterranean ecosystems. - NATO ASI Ecological Sciences, Series G 15: 305-327. - Springer-Verlag, Berlin, New York.

38. Rejeb M.N., Laffray D., Louguet P. 1991, Modification de la conductance stomatique de diverses origines tunisiennes de caroubier (Ceratonia siliqua L.) soumises à une contrainte hydrique prolongée. L'amélioration des plan tes pour l'adaptation aux milieux arides. Ed. AUPELF-UREF. John Libbey Eurotext. Paris, 1991, pp : 149-158.

39. Ducrey M., 1988. Réaction à la sécheresse de quelques essences forestières méditerranéennes. Rev. For. Fra. 40 [5] : 359-370.

40. Hopkins G., 2003. Physiologie végétale. 2ème édition traduite en français par S. Rambour. Edition De Boeck, Bruxelles, Belgique, 514 p.

41. Saiki S., Ishida A., Yoshimura K.\& Yazaki K. 2017. Physiological mechanisms of drought-induced tree die-off in relation to carbon, hydraulic and respiratory stress in a drought tolerant woody plant . Scientific RepoRts I 7: 2995 I DOI:10.1038/s41598017-03162-5 , pp: 1-7.

42. Ducrey M. 1994. Adaptation du cèdre de l'Atlas (Cedrus atlantica Manetti) au climat méditerranéen : aspects écophysiologiques de sa réaction à la sécheresse. An. Rech. For. Du Maroc. 27 : 140-152.

43. Kozlowski T.T., 1992. Carbohydrates sources and sinks in woody plants. The Botanical Review, 58 [2] : 107-222.

44. Pradal F. 1979. Variabilité génétique et écophysiologique du cèdre. Mémoire de fin d'étude a l'E.N.I.T.R.E.F. 89p.

45. Aoujdad J, Abbas Y., Hanane S., Ouajdi M., Bouther B., Mounir F., Zine El Abidine A., Fadli M. 2015. Substrate effect on the growth of seedlings of four 
provenances of Atlas cedar (Cedrus atlantica M.) in plant nursery. J. Mater. Environ. Sci., 6 [10], pp: 2817- 2824.

46. Fotelli M.N., Radoglou K.M., Constantinidou H-I.A. 2000. Water stress responses of seedlings of four Mediterranean oak species. Tree Physiology, 20, pp: 1065-1075.

47. Mediavilla S., Escudero A. 2004. Stomatal responses to drought of mature trees and seedlings of two cooccurring Mediterranean oaks. Forest Ecology and Management , 187 pp:281-294

48. Sala A, Tenhunen J.D. 1994. Site-specific water relations and stomata1 response of Quercus ilex in a Mediterranean watershed, Tree Physiology, 14, pp: 601-617.

49. Lamhamedi M.S., Ammari Y., Fecteau B., Fortin J.A., et Margolis H., 2000. Problématique des pépinières forestières en Afrique du nord et stratégies d'orientation. Cahier d'études et de recherches francophones/ Agricultures. Volume 9 [5], pp : 369 380 . 